\title{
Time series analysis of water consumption in the Hohoe municipality of the Volta region, Ghana
}

\author{
S. K. Amponsah ${ }^{2}$, D. Otoo ${ }^{1 *}$, C. A. K. Todoko ${ }^{2}$ \\ ${ }^{1}$ Department of Mathematics, University of Energy and Natural Resources, Sunyani, Ghana \\ ${ }^{2}$ Department of Mathematics, Kwame Nkrumah University of Science and Technology, Kumasi, Ghana \\ *Corresponding author E-mail: dominicotoo@ rocketmail.com
}

Copyright $\odot 2015$ D. Otoo et al. This is an open access article distributed under the Creative Commons Attribution License, which permits unrestricted use, distribution, and reproduction in any medium, provided the original work is properly cited.

\begin{abstract}
Water is considered as a lifeline of all living things, especially humans; hence its availability is a critical component in the measurement of human wellbeing through the Human Development Index (HDI). Its production and distribution in Ghana, particularly in the Hohoe Municipality of the Volta Region is a challenge. This study seeks to identify the bestfit time series model to the water consumption data in the Hohoe Municipality and to forecast water consumption in the Municipality. This underpins the development of a time-series model for forecasting water consumption levels of the residents, institutions and businesses in the municipality. Several time series models, including AR, MA, ARMA, ARIMA and SARIMA were fitted to the data, and it emerged that the most adequate model for the data was ARIMA (2, 1 , and 2). The model was then used to forecast the consumption for the next four years, to advise Ghana Water Company Limited in the municipality to meet the demand of the people.
\end{abstract}

Keywords: Human Development; Municipality; ARIMA Model; Forecasting; Consumption.

\section{Introduction}

Water is required by all living creatures for survival. It is also required for economic growth and development [3]. According to the UN World Water Development Report (2006), water is an essential life-sustaining element. It pervades our lives and is deeply embedded in our cultural backgrounds." The achievement of the millennium development goals depends largely on improved water supply and sanitation in the developing countries in which Ghana is not an exception. The World Health Organisation [3] recommended that 75 litres of water a day is necessary to protect against household diseases and 50 litres a day necessary for basic family sanitation. The international consumption figures released by the 4th World Water Forum [11] indicate that a person living in an urban area uses an average of 250 litres/day. With these figures in mind, experts need to factor in population increase and forecast for the production and consumption of water in the area.

The Hohoe Municipality is one of the eighteen districts in the Volta Region of Ghana with Hohoe as its capital and administrative centre. According to the Ghana Statistical Service report (2010), it has a population of 262,046 made up of 126,239 and 135,807 males and females respectively. The population size has grown by almost $81 \%$ from the year 2000. In terms of water supply in the municipality, the Ghana Water Company Limited and DANIDA have been effective in resolving many problems identified in 1992 were more than $60 \%$ of the population lack good drinking water and sanitation facilities. Very old machines, broken-down hand pumps and other equipment have either been replaced or repaired for efficient water production and distribution in the municipality.

Majority of the people of the Municipality (about 65\%) are engaged in agricultural production. The technology employed in agricultural production in the municipality is largely the traditional cutlass and hoe. Mechanised farming is very limited and the rate of adoption of other agricultural-related technologies is equally low. Farming is entirely rainfed as there are no irrigation facilities, and this culminates in low productivity. Access roads to farming centres are also 
poor thus hampering the marketing of the products. These together with the absence of storage facilities give rise to high post-harvest losses.

\section{Related works}

Initial works in water demand forecasting have included regression and time series analyses by Jain [5]. Salas [10] formulated a general time series model for water use on any time interval. Their model contains a polynomial trend in mean and standard deviation, a periodic mean and standard deviation, and an autoregressive (AR) short-memory component. The model residuals were fitted by the normal, log-normal, or gamma distributions. They also calculated the cross-correlation and coherence functions between monthly water use and rainfall and between monthly water use and temperature.

Maidment [8] created a time-series model based on precipitation and temperature and included the Box-Jenkins transfer function. A year after, they applied the model to nine cities in three states in USA [9], their models achieved overall correlation of determination (R2) ranging from 61 to 96 percent. Zhou [12] developed a forecasting model for Melbourne, Australia. Using a time-series analysis, they proposed that demand was comprised of base, seasonal, climatic, and persistence components.

Gato [2] used a similar time series model as Zhou [12] but added temperature and precipitation thresholds into their model. Aside from time-series analysis, more complicated algorithms have been used to forecast demand. Lertpalangsunti [7] created a model using the artificial neural network (ANN) and applied the model in an attempt to predict the demand for the city of Regina.

Bougadis [1] compared a time-series approach and ANN in demand prediction for the city of Ottawa. Khan [6] compared the support vector machine with ANN and an autoregressive model to forecast water level for Lake Erie. Hererra [4] compared the results from four methods, including ANN, projection pursuit regression, multivariate adaptive regression splines, and random forests and support vector regression in the forecasting of water demand for a water district servicing approximately 5000 customers in south-eastern Spain.

\section{Research methodology}

The demand for water can be influenced by certain factors, such as changes in weather conditions, changes in yearly patterns, population change, and industrial and agricultural activities. The research looks at forecasting the demand for water based on population change using time series based on MA, AR, ARMA, and ARIMA models.

\subsection{Autocorrelation function (ACF)}

Autocorrelation refers to the correlation of a time series with its own past and future values.

Autocorrelation is also called "lagged correlation" or "serial correlation," which refers to the correlation between members of a series of numbers arranged in time.

The first- order autocorrelation coefficient is the simple coefficient of the first $\mathrm{N}-1$ observations, $\mathrm{t}=1,2 \ldots \mathrm{N}-1 X_{t}: \mathrm{t}=2$, $3 \ldots$ N. The correlation between $X_{t}$ and $X_{t+1}$ is given by,

$r_{1}=\frac{\sum_{t=1}^{N-1}\left(x_{t}-X_{1}\right)\left(x_{t+1}-X_{2}\right)}{\left[\sum_{t=1}^{N-1}\left(x_{t}-X_{1}\right)^{2}\right]\left[\sum_{t=1}^{N-1}\left(x_{t}-X_{1}\right)^{2}\right]}$

$r_{1}=\frac{\sum_{t=1}^{N-1}\left(x_{t}-X\right)\left(x_{t+1}-X\right)}{\sum_{t=1}^{N}\left(x_{t}-X\right)^{2}}$

Where is the mean of the first $\mathrm{N}-1$ observations. As the correlation coefficient given above measure correlation between successive observations, it is called the autocorrelation coefficient or serial correlation coefficient. For $\mathrm{N}$ reasonably large, the difference between the sub-period means $X_{1}$ and $X_{2}$ can be ignored and $r_{1}$ can be approximated as by Equation (3.2) can be generalised to give the correlation between observations separated by $\mathrm{k}$ years: 


$$
r_{k}=\frac{\sum_{t=1}^{N=k}\left(X_{t}-X\right)\left(X_{t+k}-X\right)}{\sum_{t=1}^{N}\left(X_{t}-X\right)^{2}}
$$

\subsection{Partial autocorrelated function}

Partial autocorrelation function measures the degree of association between $\mathrm{Yt}$ and $\mathrm{Yt}+\mathrm{k}$ when the effect of another time lags on $\mathrm{Y}$ are held constant. The Partial Autocorrelation Function PACF denoted by the set of partial autocorrelations at various lags $\mathrm{k}$ are defined by $(\mathrm{k}=1,2,3 \ldots)$. The set of partial autocorrelations at various lags $\mathrm{k}$ are defined by.

$r_{k k}=\frac{r_{k}-\sum_{j=1}^{k-1} r_{k-1, j} r_{k-1}}{1-\sum_{j=1}^{k-1} r_{k-1, j} r_{j}}$

Where, $r_{k, j}=r_{k-1, j-r_{k k}} r_{k-1}, k-1, j=1,2 \ldots \mathrm{k}-1$

Specifically, partial autocorrelations are useful in identifying the order of an autoregressive Model. The partial autocorrelation of an $\mathrm{AR}(\mathrm{p})$ process is zero at lag $\mathrm{p}+1$ and greater.

\subsection{Autoregressive (AR) models}

An autoregressive model is simply a linear regression of the current value of the series against one or more prior values of the series. The value of $p$ is called the order of the AR model. AR models can be analyzed with one of the various methods, including standard linear least squares techniques. They also have a straightforward interpretation. A common approach for modelling univariate time series is the autoregressive (AR) model:

$$
X_{t}=\mu+\phi_{1} X_{t-1}+\phi_{2} X_{t-2}+\ldots+\phi_{p} X_{t-p}+A_{t}
$$

Where Xt is the time series, at is white noise, and with $\mu$ denoting the process mean. An autoregressive model of order p, denoted by AR (p) with mean zero is generally given by the equation:

$$
X_{t}=\phi_{1} X_{t-1}+\phi_{2} X_{t-2}+\ldots+\phi_{p} X_{t-p}+\varepsilon_{t}
$$

Or

$$
X_{t}=\phi_{1} L_{1}+\phi_{2} L_{2}+\ldots+\phi_{p} L_{p}+\varepsilon_{t}
$$

When $\phi(L) X_{t}=\varepsilon_{t}$

$$
\phi(u)=1-\phi_{1} u^{1}-\phi_{2} u^{2}-\ldots-\phi_{p} u^{p}
$$

Where $\mathrm{L}$, is the lag operator $\phi_{1}, \phi_{2}, \ldots, \phi_{p}$ are constants with $\phi_{p} \neq 0$ are the autoregressive model parameters and $\varepsilon_{t}$ is the random shock or white noise process, with mean zero and variance $\sigma_{\varepsilon}^{2}$. Replace Xt by Xt $-\mu$. That is

$$
\begin{aligned}
& X_{t}-\mu=\phi_{1}\left(X_{t-1}+\mu\right)+\phi_{2}\left(X_{t-2}+\mu\right)+\ldots+\phi_{p}\left(X_{t-p}+\mu\right)+\varepsilon_{t} \\
& X_{t}=\alpha+\phi_{1} X_{t-1}+\phi_{2} X_{t-2}+\ldots+\phi_{p} X_{t-p}+\varepsilon_{t}
\end{aligned}
$$

Where $\alpha=\mu\left(1-\phi_{1}-\phi_{2}-\ldots-\phi_{p}\right)$

\subsection{Moving average (MA) models}

Moving Average (MA) is another common approach for modelling univariate time series. Moving average model of order $\mathrm{q}$ is (MA (q)) is given by 
$X_{t}=\mu+A_{t}+\theta_{1} A_{t-1}+\theta_{2} A_{t-2}+\ldots+\theta_{q} A_{t-q}$

Where $\theta_{1}, \theta_{2}, \ldots \theta_{q}$ are constants with $\theta_{q} \neq 0 \mathrm{Xt}$ is the time series, $\mu$ is the mean of the series, $A_{t-i}$ and are white noise.

A moving average model of order $\mathrm{q}$, with mean zero, denoted by MA (q) is generally given.

By:

$X_{t}=A_{t}+\theta_{1} A_{t-1}+\theta_{2} A_{t-2}+\ldots+\theta_{q} A_{t-q}$

where $A_{t} \square W N\left(0, \sigma^{2}\right)$

The MA (q) process can also be written in the following equivalent form $X_{t}=\theta(u) A_{t}$ where the moving average operator

$\theta(u)=1+\theta_{1} u+\theta_{2} u^{2}+\ldots+\theta_{q} u^{q}$

\subsection{Autoregressive moving average (ARMA) models}

Autoregressive and Moving Average processes can be combined to obtain a very flexible Class of univariate processes (proposed by Box and Jenkins), known as ARMA processes. The time series Xt is an ARMA (p, q) process, if it is stationary and

$$
X_{t}=\phi_{1} X_{t-1}+\phi_{2} X_{t-2}+\ldots+\phi_{p} X_{t-p}+\varepsilon_{t}+X_{t}=A_{t}+\theta_{1} A_{t-1}+\theta_{2} A_{t-2}+\ldots+\theta_{q} A_{t-q}
$$

\section{Data analysis and results}

This section applied the models described in Section 4 to forecast water consumption in Hohoe. A fortnight demand data in (m3) obtained from Ghana Water Company Limited for the years 2009, 2010, 2011 and 2012 were used to forecast for the next four years.

Table 1: Fortnights Consumption of Water in (M3) from Hohoe Municipality

\begin{tabular}{|c|c|c|c|c|c|c|c|}
\hline \multirow{2}{*}{$\begin{array}{l}2009 \\
\text { Fortnights }\end{array}$} & \multirow[b]{2}{*}{ Data } & \multicolumn{2}{|l|}{2010} & \multicolumn{2}{|l|}{2011} & \multicolumn{2}{|l|}{2012} \\
\hline & & Fortnights & Data & Fortnights & Data & Fortnights & Data \\
\hline 1 & 22245 & 28 & 25647 & 55 & 25721 & 81 & 30264 \\
\hline 2 & 23415 & 29 & 24040 & 56 & 22025 & 82 & 29400 \\
\hline 3 & 18319 & 30 & 22846 & 57 & 24366 & 83 & 29443 \\
\hline 4 & 20675 & 31 & 23672 & 58 & 22419 & 84 & 26045 \\
\hline 5 & 23220 & 32 & 24257 & 59 & 24010 & 85 & 24479 \\
\hline 6 & 21514 & 33 & 24883 & 60 & 24326 & 86 & 29499 \\
\hline 7 & 22398 & 34 & 22570 & 61 & 22700 & 87 & 29401 \\
\hline 8 & 21639 & 35 & 23668 & 62 & 23267 & 88 & 28795 \\
\hline 9 & 21852 & 36 & 23587 & 63 & 24127 & 89 & 25445 \\
\hline 10 & 19862 & 37 & 23903 & 64 & 24480 & 90 & 28226 \\
\hline 11 & 22953 & 38 & 24212 & 65 & 24519 & 91 & 27472 \\
\hline 12 & 21338 & 39 & 21968 & 66 & 22486 & 92 & 30105 \\
\hline 13 & 22356 & 40 & 17108 & 67 & 22368 & 93 & 29269 \\
\hline 14 & 22904 & 41 & 22043 & 68 & 21314 & 94 & 30946 \\
\hline 15 & 22161 & 42 & 25449 & 69 & 24226 & 95 & 30434 \\
\hline 16 & 23786 & 43 & 22464 & 70 & 22994 & 96 & 27631 \\
\hline 17 & 22827 & 44 & 23261 & 71 & 23972 & 97 & 29408 \\
\hline 18 & 21072 & 45 & 22546 & 72 & 22151 & 98 & 28826 \\
\hline 19 & 21044 & 46 & 21541 & 73 & 23032 & 99 & 27922 \\
\hline 20 & 23374 & 47 & 21414 & 74 & 21173 & 100 & 26002 \\
\hline 21 & 22245 & 48 & 19759 & 75 & 22133 & 101 & 28573 \\
\hline 22 & 22551 & 49 & 19063 & 76 & 21766 & 102 & 30056 \\
\hline 23 & 24274 & 50 & 21036 & 77 & 28054 & 103 & 31325 \\
\hline 24 & 24086 & 51 & 24270 & 78 & 29265 & 104 & 29275 \\
\hline 25 & 25394 & 52 & 24599 & 79 & 16325 & 105 & 30330 \\
\hline 26 & 23241 & 53 & 25358 & 80 & 30179 & 106 & 30507 \\
\hline
\end{tabular}




\subsection{Preliminary analysis}

A dimension of the preliminary analysis for examining non-stationarity of the data is by considering the trend analysis plot of 106 fortnight water consumption between 2009 and 2012 as shown in Figure 4.1.

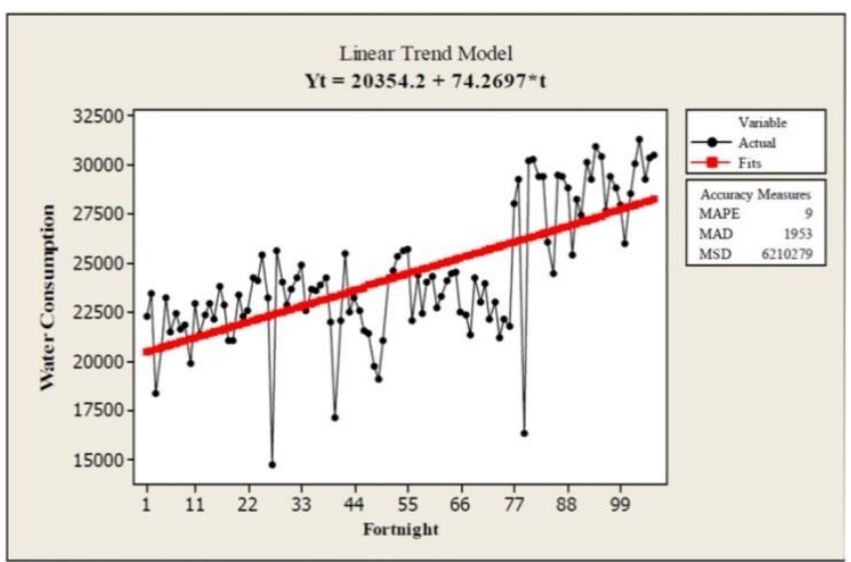

Fig. 4.1: Trend in Fortnight Water Consumption between 2009 and 2012

It is revealed from Figure 4.1 that water consumption in the Hohoe Municipality between2009 and 2012 have been largely non-stationary. The mean is not constant throughout the series as it assumes a fairly stable mean till 26th fortnight. The 27th, 40th and 79th fortnights recorded significantly low water consumption, perhaps due to the insufficient water provision in the municipality. Furthermore, Moving Average (MA) analyses for lags 2, 4 and 8 are in Figures 4.2, 4.3, and 4.4. A comparison of their respective accuracy measures indicates that MA (8) better fits the data.

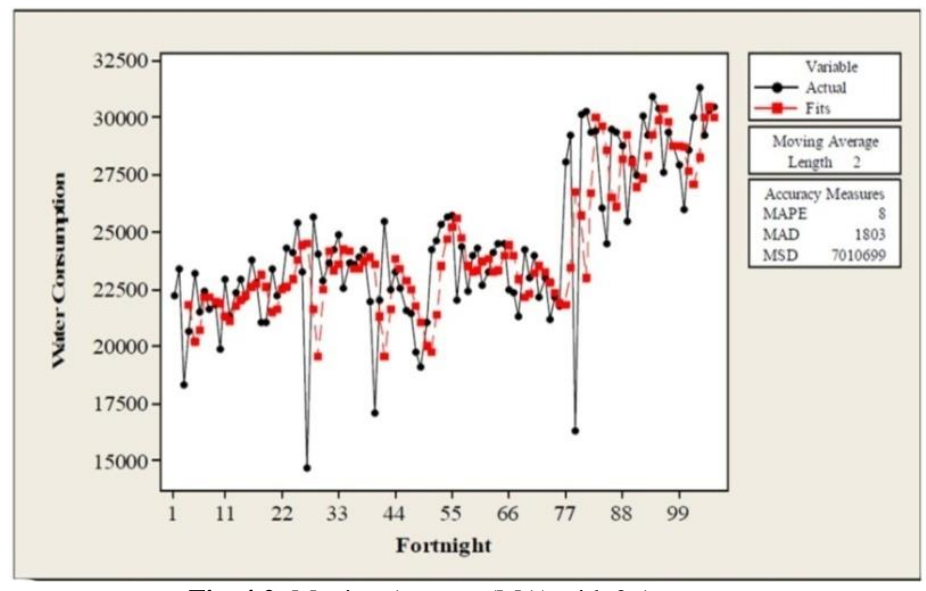

Fig. 4.2: Moving Average (MA) with 2 Averages.

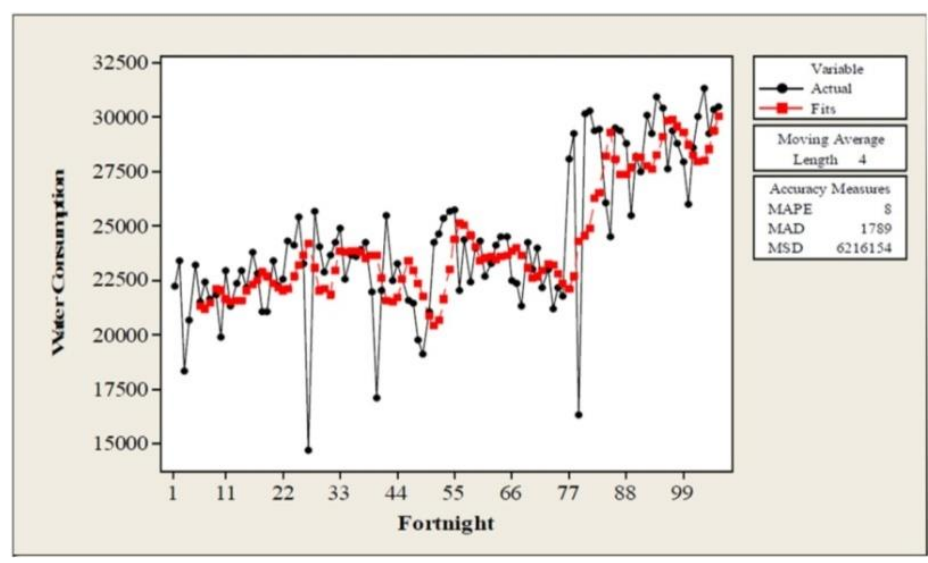

Fig. 4.3: Moving Average (MA) with 4 Averages 


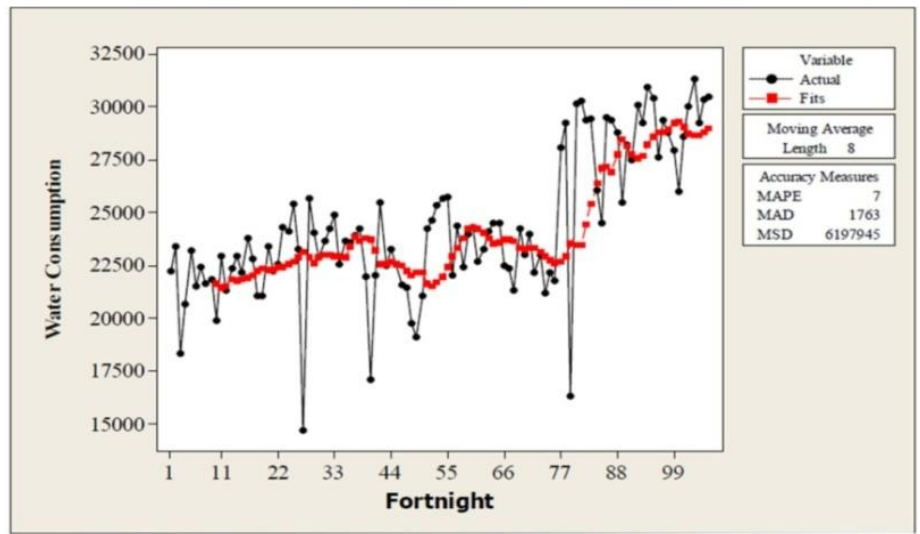

Fig. 4.4: Moving Average (Ma) with 8 Averages

The next step in the model-building procedure is to determine the order of the AR and MA for both seasonal and nonseasonal components. This was suggested by the sample ACF and PACF plots based on the Box-Jenkins approach. From Figure 4.2, the correlations are significant for a large number of lags but perhaps the autocorrelations at lags 2 or and above are merely due to the propagation of the autocorrelation at lag 1 . This is confirmed by the PACF plot.

The ACF and PACF plots in Figures 4.5 and 4.6 respectively suggest that $q=2$ or 3 , and

$\mathrm{p}=2$ would be needed to describe this data set as coming from a non-seasonal moving average and autoregressive process respectively.

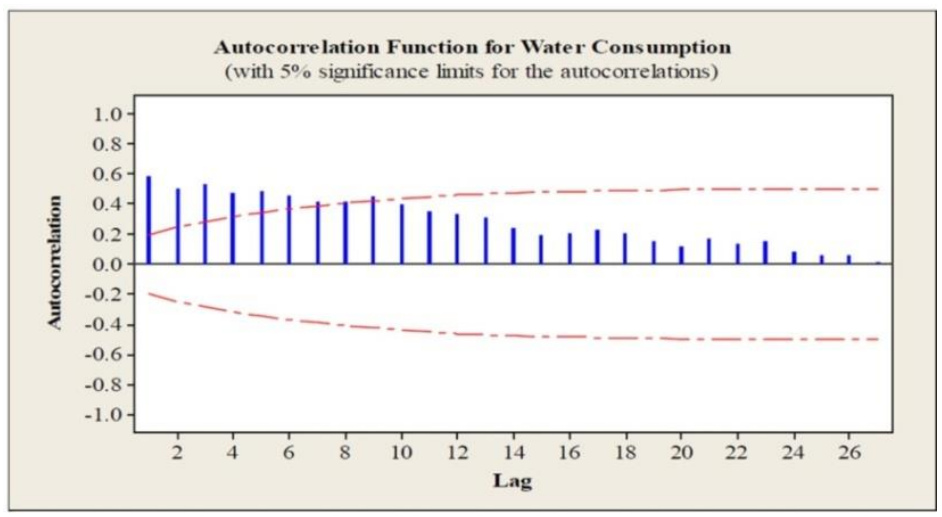

Fig. 4.5: ACF for First Order Differencing.

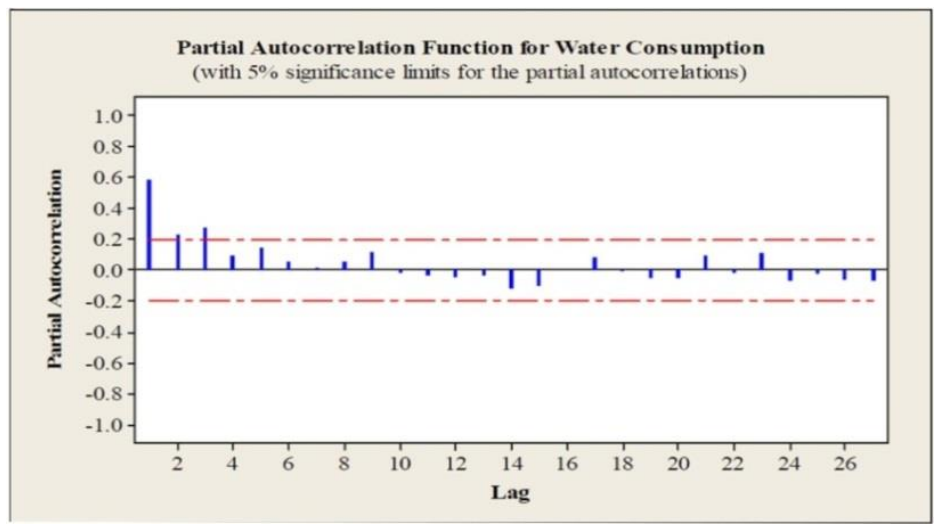

Fig. 4.6: PACF for First Order Differencing

\subsection{Seasonal ARIMA model estimations}

At this stage, it is important also to consider the seasonality of the data by adopting the seasonal ARIMA models. Looking at the seasonal lags, both ACF and PACF spike at seasonal lag 27 (because there are 27 fortnights in a year) and drop to zero for other seasonal lags suggesting that $\mathrm{Q}=1$ or 2 and $\mathrm{P}=0$ or 1 with $\mathrm{d}=1$ would be needed to describe these data as coming from a seasonal moving average and autoregressive process. Therefore, 15 proposed SARIMA models are presented in Table 4.12 with their corresponding p-values, Chi-square values and degree of freedom. 
Table 4.2: Suggested Sarima Models

\begin{tabular}{llll}
\hline Model & p-value & Chi-Square & Df \\
\hline ARIMA $(0,1,1)(1,0,1) 27$ & 0.557 & 7.8 & 9 \\
ARIMA $(1,1,1)(0,1,1) 27$ & 0.798 & 3.8 & 7 \\
ARIMA $(1,1,3)(1,0,1) 27$ & 0.793 & 2.4 & 5 \\
ARIMA $(1,1,3)(1,0,1) 27$ & 0.699 & 2.2 & 4 \\
ARIMA $(1,3)(0,1,0) 27$ & 0.427 & 6.0 & 6 \\
ARIMA $(2,1,2)(0,1,0) 27$ & 0.859 & 3.3 & 7 \\
ARIMA $(2,1,1)(1,1,1) 27$ & 0.534 & 5.1 & 6 \\
ARIMA $(2,1,2)(1,0,1) 27$ & 0.774 & 2.5 & 5 \\
ARIMA $(2,1,2)(0,0,1) 27$ & 0.846 & 2.7 & 4 \\
ARIMA $(2,1,3)(1,0,1) 27$ & 0.699 & 2.2 & 6 \\
ARIMA $(2,1,2)(1,0,0) 27$ & 0.915 & 2.0 & 3 \\
ARIMA $(4,1,3)(0,0,1) 27$ & 0.614 & 1.8 & 5 \\
ARIMA $(3,1,1)(1,1,1) 27$ & 0.011 & 15.0 & 5 \\
ARIMA $(2,2,3)(0,0,1) 27$ & 0.186 & 7.5 & 5 \\
ARIMA $(2,2,2)(1,0,1) 27$ & 0.006 & 16.2 & \\
\hline
\end{tabular}

A critical comparison of the models based on their respective p-values and Chi-Square values shows, that seasonal ARIMA $(2,1,2)(1,0,0) 27$ is the appropriate model that best fitted the fortnight water consumption data in the Hohoe Municipality in the Volta Region of Ghana.

This would, however, be compared with the non-seasonal ARIMA model for final selection of the most adequate and parsimonious model.

\subsection{Model evaluation and selection}

From the aforementioned, we have identified two good models, namely, a non-seasonal and seasonal ARIMA model as shown in Tables 4.13 and 4.14 respectively for comparison and selection. We used the conditional-sum-of-squares to find starting values of parameters, then do the Maximum Likelihood Estimate (MLE) for the proposed models. The procedure for choosing these models relied on choosing the model with the maximum p-values for the Ljung-Box statistic (more than 5\% as a rule of thumb) and minimum Chi-square values.

Comparing the non-seasonal ARIMA and the seasonal ARIMA models, it can be concluded that the non-seasonal model of $(2,1,2)$ is somewhat adequate than the seasonal ARIMA model of $(2,1,2)(1,0,0) 27$. Hence, ARIMA $(2,1$, 2 ) is the best model and plausible time series model for the fortnight water consumption because of its high $\mathrm{p}$ and least Chi-Square values of 0.955 and 2.0 respectively.

Table 4.3: ARIMA $(2,1,2)$

\begin{tabular}{llccc}
\hline Type & Coefficient & SE & $\mathrm{t}$ & $\mathrm{p}$ \\
\hline Constant & 126.59 & 56.37 & 2.25 & 0.027 \\
AR 1 & -0.4754 & 0.5375 & -0.88 & 0.379 \\
AR 2 & -0.0800 & 0.1508 & -0.53 & 0.597 \\
MA 1 & 0.2946 & 0.5340 & 0.55 & 0.582 \\
MA 2 & 0.4659 & 0.4789 & 0.97 & 0.333 \\
\hline
\end{tabular}

$\chi^{2}=2.1 ; \mathrm{p}=0.955 ; \mathrm{df}=7$

Table 4.4: Estimates of Parameters for SARIMA $(2,1,2)(1,0,0) 27$

\begin{tabular}{lcccc}
\hline Variable & Coefficients & SE & $\mathrm{t}$ & $\mathrm{p}$ \\
\hline Constant & 122.55 & 60.72 & 2.02 & 0.046 \\
AR 1 & -0.5697 & 0.4053 & -1.41 & 0.163 \\
AR 2 & -0.1006 & 0.1410 & -0.71 & 0.477 \\
SAR 27 & 0.1811 & 0.1199 & 1.51 & 0.134 \\
MA 1 & 0.2128 & 0.3988 & 0.53 & 0.595 \\
MA 2 & 0.5279 & 0.3600 & 1.47 & 0.146 \\
\hline
\end{tabular}

$\mathrm{p}=0.735, \chi^{2}=4.4, \mathrm{df}=6$

\subsection{Diagnostic analysis}

The diagnostic analyses using the ACF of residuals, PACF residuals, and the normal probability plot of the residuals as shown in Figures 4.7, 4.8, 4.9 and 4.10 reveal that the residuals of the model have zero mean and constant variance. The ACF of the residuals depicts that the autocorrelation of the residuals are all zero, that is to say, they are uncorrelated. 
Hence, it can be concluded that there is a constant variance among residuals of the selected model, and the true mean of the residuals is approximately equal to zero. Thus, the selected model satisfies all the model assumptions. Since the ARIMA $(2,1,2)$ satisfies all the necessary assumptions, it can be inferred that the model provides an adequate representation of the data. Hence, the predictive model would be formulated from the parameter estimates in Table 4.13.

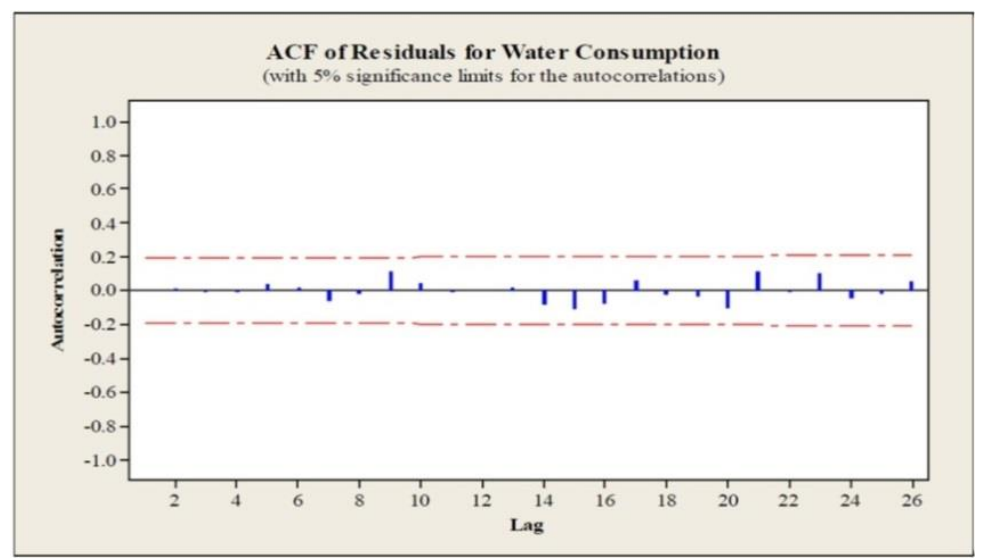

Fig. 4.7: ACF Diagnostic Plot of the Residuals for ARIMA $(2,1,2)$ Model.

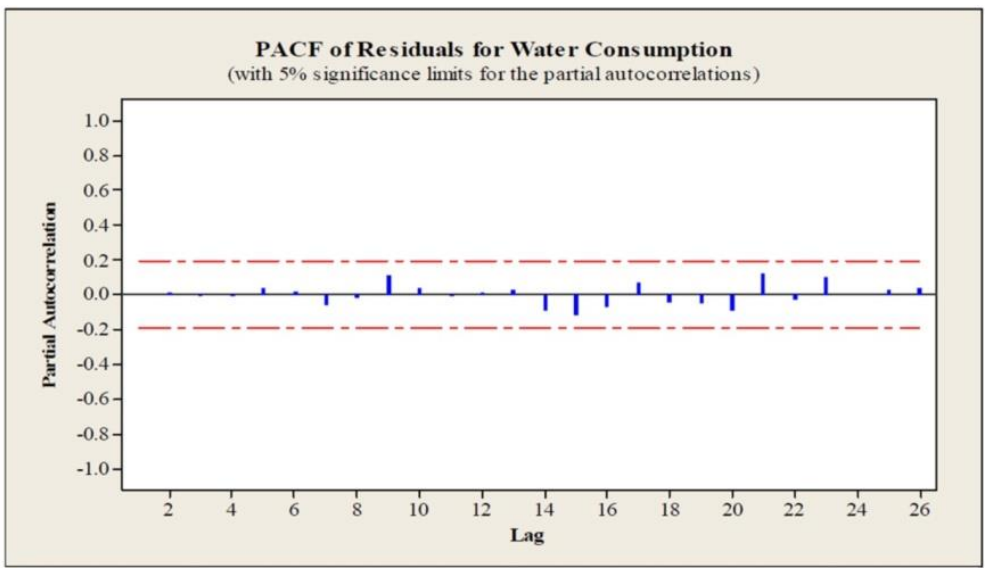

Fig. 4.8: PACF Diagnostic Plot of the Residuals for ARIMA $(2,1,2)$ Model.

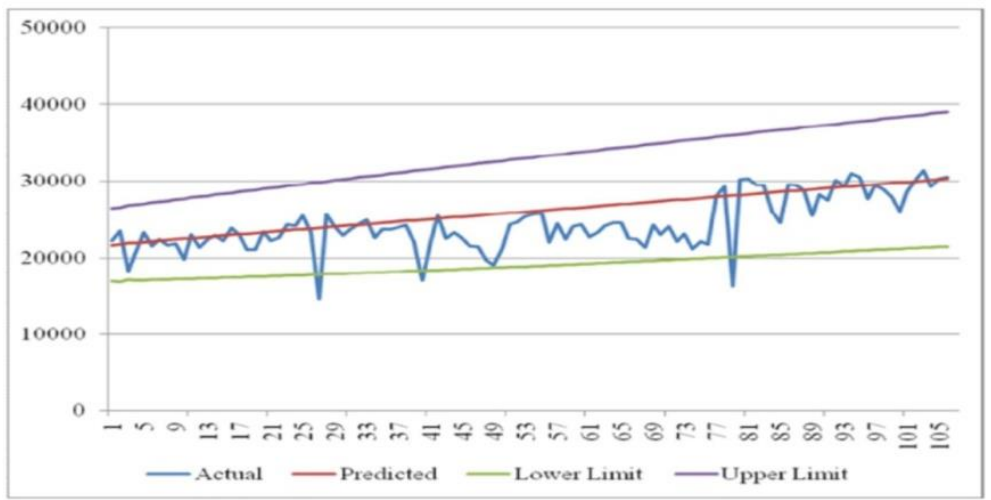

Fig. 4.9: Actual and Predicted Water Consumption Using ARIMA $(2,1,2)$

\section{Discussions (forecasting)}

Table 4.15 summarises the forecasted values of water consumption in the Municipality over the period of January 2013 to December 2016 fortnightly with $95 \%$ confidence level using the ARIMA $(2,1,2)$ model, which has a higher p-value of 0.955 (thus, greater than alpha value of 0.05 ) indicating that it is the best model according to Modified Box-Pierce (Ljung-Box) Chi-Square statistic. 
Table 4.5: Forecasted Fortnight Water Consumption for the Next 4 Years

\begin{tabular}{|c|c|c|c|c|}
\hline \multirow[b]{2}{*}{ Year } & \multirow[b]{2}{*}{ Fortnight } & \multirow[b]{2}{*}{ Forecast } & \multicolumn{2}{|c|}{$95 \% \mathrm{CI}$} \\
\hline & & & Lower Limit & Upper Limit \\
\hline 2013 & $1 \mathrm{st}$ & 29809.6 & 25129.4 & 34489.7 \\
\hline 2013 & $2 \mathrm{nd}$ & 29995.4 & 25193.0 & 34797.7 \\
\hline 2013 & $3 \mathrm{rd}$ & 30089.4 & 25281.3 & 34897.5 \\
\hline 2013 & 4th & 30156.4 & 25260.5 & 35052.4 \\
\hline 2013 & 5 th & 30243.6 & 25303.0 & 35184.3 \\
\hline 2013 & 6th & 30323.4 & 25328.8 & 35318.0 \\
\hline 2013 & 7 th & 30405.1 & 25358.8 & 35451.3 \\
\hline 2013 & 8th & 30486.5 & 25389.1 & 35583.8 \\
\hline 2013 & 9th & 30567.8 & 25419.7 & 35716.0 \\
\hline 2013 & 10th & 30649.2 & 25450.9 & 35847.5 \\
\hline 2013 & 11th & 30730.6 & 25482.5 & 35978.7 \\
\hline 2013 & 12 th & 30812.0 & 25514.6 & 36109.3 \\
\hline 2013 & 13th & 30893.4 & 25547.2 & 36239.5 \\
\hline 2013 & 14th & 30974.7 & 25580.2 & 36369.3 \\
\hline 2013 & 15 th & 31056.1 & 25613.7 & 36498.6 \\
\hline 2013 & 16 th & 31137.5 & 25647.5 & 36627.5 \\
\hline 2013 & 17 th & 31218.9 & 25681.8 & 36756.0 \\
\hline 2013 & 18th & 31300.3 & 25716.5 & 36884.1 \\
\hline 2013 & 19th & 31381.7 & 25751.5 & 37011.8 \\
\hline 2013 & 20th & 31463.0 & 25787.0 & 37139.1 \\
\hline 2013 & $21 \mathrm{st}$ & 31544.4 & 25822.8 & 37266.1 \\
\hline 2013 & 22nd & 31625.8 & 25858.9 & 37392.7 \\
\hline 2013 & $23 r d$ & 31707.2 & 25895.4 & 37518.9 \\
\hline 2013 & 24 th & 31788.6 & 25932.3 & 37644.9 \\
\hline 2013 & 25 th & 31870.0 & 25969.5 & 37770.4 \\
\hline 2013 & 26th & 31951.3 & 26007.0 & 37895.7 \\
\hline 2013 & 27 th & 32032.7 & 26044.8 & 38020.6 \\
\hline 2014 & $1 \mathrm{st}$ & 32114.1 & 26083.0 & 38145.2 \\
\hline 2014 & $2 \mathrm{nd}$ & 32195.5 & 26121.5 & 38269.5 \\
\hline 2014 & $3 \mathrm{rd}$ & 32276.9 & 26160.2 & 38393.5 \\
\hline 2014 & 4th & 32358.3 & 26199.3 & 38517.2 \\
\hline 2014 & 5 th & 32439.6 & 26238.6 & 38640.6 \\
\hline 2014 & 6th & 32521.0 & 26278.3 & 38763.8 \\
\hline 2014 & 7th & 32602.4 & 26318.2 & 38886.6 \\
\hline 2014 & 8th & 32683.8 & 26358.4 & 39009.2 \\
\hline 2014 & 9th & 32765.2 & 26398.8 & 39131.5 \\
\hline 2014 & 10th & 32846.5 & 26439.5 & 39253.6 \\
\hline 2014 & 11th & 32927.9 & 26480.5 & 39375.4 \\
\hline 2014 & 12 th & 33009.3 & 26521.7 & 39496.9 \\
\hline 2014 & 13th & 33090.7 & 26563.2 & 39618.2 \\
\hline 2014 & 14 th & 33172.1 & 26604.9 & 39739.3 \\
\hline 2014 & 15 th & 33253.5 & 26646.8 & 39860.1 \\
\hline 2014 & 16th & 33334.8 & 26689.0 & 39980.7 \\
\hline 2014 & 17 th & 33416.2 & 26731.4 & 40101.0 \\
\hline 2014 & 18th & 33497.6 & 26774.1 & 40221.2 \\
\hline 2014 & 19th & 33579.0 & 26816.9 & 40341.1 \\
\hline 2014 & 20th & 33660.4 & 26860.0 & 40460.7 \\
\hline 2014 & $21 \mathrm{st}$ & 33741.8 & 26903.3 & 40580.2 \\
\hline 2014 & 22nd & 33823.1 & 26946.8 & 40699.5 \\
\hline 2014 & $23 r d$ & 33904.5 & 26990.5 & 40818.5 \\
\hline 2014 & 24th & 33985.9 & 27034.4 & 40937.4 \\
\hline 2014 & 25 th & 34067.3 & 27078.5 & 41056.0 \\
\hline 2014 & 26th & 34148.7 & 27122.8 & 41174.5 \\
\hline 2014 & 27 th & 34230.1 & 27167.3 & 41292.8 \\
\hline 2015 & $1 \mathrm{st}$ & 34311.4 & 27212.0 & 41410.8 \\
\hline 2015 & 2 nd & 34392.8 & 27256.9 & 41528.7 \\
\hline
\end{tabular}




\begin{tabular}{|c|c|c|c|c|}
\hline 2015 & $3 \mathrm{rd}$ & 34474.2 & 27302.0 & 41646.4 \\
\hline 2015 & 4 th & 34555.6 & 27347.3 & 41763.9 \\
\hline 2015 & 5 th & 34637.0 & 27392.7 & 41881.2 \\
\hline 2015 & 6th & 34718.3 & 27438.3 & 41998.4 \\
\hline 2015 & 7th & 34799.7 & 27484.1 & 42115.4 \\
\hline 2015 & 8th & 34881.1 & 27530.1 & 42232.2 \\
\hline 2015 & 9th & 34962.5 & 27576.2 & 42348.8 \\
\hline 2015 & 10 th & 35043.9 & 27622.5 & 42465.3 \\
\hline 2015 & 11 th & 35125.3 & 27669.0 & 42581.6 \\
\hline 2015 & 12 th & 35206.6 & 27715.6 & 42697.7 \\
\hline 2015 & 13th & 35288.0 & 27762.4 & 42813.7 \\
\hline 2015 & 14 th & 35369.4 & 27809.3 & 42929.5 \\
\hline 2015 & 15 th & 35450.8 & 27856.4 & 43045.2 \\
\hline 2015 & 16th & 35532.2 & 27903.7 & 43160.7 \\
\hline 2015 & 17 th & 35613.6 & 27951.1 & 43276.0 \\
\hline 2015 & 18th & 35694.9 & 27998.6 & 43391.3 \\
\hline 2015 & 19th & 35776.3 & 28046.3 & 43506.3 \\
\hline 2015 & 20th & 35857.7 & 28094.2 & 43621.2 \\
\hline 2015 & $21 \mathrm{st}$ & 35939.1 & 28142.2 & 43736.0 \\
\hline 2015 & 22 nd & 36020.5 & 28190.3 & 43850.6 \\
\hline 2015 & $23 r d$ & 36101.9 & 28238.6 & 43965.1 \\
\hline 2015 & 24 th & 36183.2 & 28287.0 & 44079.5 \\
\hline 2015 & 25 th & 36264.6 & 28335.6 & 44193.7 \\
\hline 2015 & 26 th & 36346.0 & 28384.3 & 44307.8 \\
\hline 2015 & 27 th & 36427.4 & 28433.1 & 44421.7 \\
\hline 2016 & $1 \mathrm{st}$ & 36508.8 & 28482.0 & 44535.5 \\
\hline 2016 & $2 n d$ & 36590.1 & 28531.1 & 44649.2 \\
\hline 2016 & $3 \mathrm{rd}$ & 36671.5 & 28580.3 & 44762.7 \\
\hline 2016 & 4th & 36752.9 & 28629.7 & 44876.2 \\
\hline 2016 & 5 th & 36834.3 & 28679.1 & 44989.5 \\
\hline 2016 & 6 th & 36915.7 & 28728.7 & 45102.6 \\
\hline 2016 & 7th & 36997.1 & 28778.4 & 45215.7 \\
\hline 2016 & 8th & 37078.4 & 28828.3 & 45328.6 \\
\hline 2016 & 9th & 37159.8 & 28878.2 & 45441.4 \\
\hline 2016 & 10th & 37241.2 & 28928.3 & 45554.1 \\
\hline 2016 & 11 th & 37322.6 & 28978.5 & 45666.7 \\
\hline 2016 & 12 th & 37404.0 & 29028.8 & 45779.1 \\
\hline 2016 & 13th & 37485.4 & 29079.2 & 45891.5 \\
\hline 2016 & 14th & 37566.7 & 29129.8 & 46003.7 \\
\hline 2016 & 15 th & 37648.1 & 29180.4 & 46115.8 \\
\hline 2016 & 16th & 37729.5 & 29231.2 & 46227.8 \\
\hline 2016 & 17 th & 37810.9 & 29282.1 & 46339.7 \\
\hline 2016 & 18th & 37892.3 & 29333.0 & 46451.5 \\
\hline 2016 & 19th & 37973.7 & 29384.1 & 46563.2 \\
\hline 2016 & 20 th & 38055.0 & 29435.3 & 46674.8 \\
\hline 2016 & $21 \mathrm{st}$ & 38136.4 & 29486.6 & 46786.2 \\
\hline 2016 & 22nd & 38217.8 & 29538.0 & 46897.6 \\
\hline 2016 & $23 \mathrm{rd}$ & 38299.2 & 29589.5 & 47008.8 \\
\hline 2016 & 24th & 38380.6 & 29641.1 & 47120.0 \\
\hline 2016 & 25 th & 38462.0 & 29692.9 & 47231.0 \\
\hline 2016 & 26 th & 38543.3 & 29744.7 & 47342.0 \\
\hline 2016 & 27 th & 38624.7 & 29796.6 & 47452.9 \\
\hline
\end{tabular}

\section{References}

[1] Bougadis, J., Adamowski, K., Diduch, R. (2005). "Short-term municipal water demand forecasting." Hydrological Processes 19, 137148.http://dx.doi.org/10.1002/hyp.5763.

[2] Gato, S., Jayasuriya, N., Roberts, P. (2007). "Temperature and rainfall thresholds for base use urban water demand modelling." Journal of Hydrology 337 (3-4), 364-376.http://dx.doi.org/10.1016/j.jhydrol.2007.02.014. 
[3] Hagan, I. (2007). Modeling the impact of small reservoirs in the Upper East Region of Ghana.MSc thesis submitted to Lund University Press, Sweden.

[4] Herrera, M., Torgo, L., Izquierdo, J., and Perez-Garcia, R. (2010). "Predictive models for forecasting hourly urban water demand." Journal of Hydrology 397, 141-150.http://dx.doi.org/10.1016/j.jhydrol.2010.04.005.

[5] Jain, A., Varshney, K., Joshi, U. (2001). "Short-term water demand forecast modelling at IIT Kanpur using artificial neural networks." Water ResourcesManagement 15, 299-321.http://dx.doi.org/10.1023/A:1014415503476.

[6] Khan, M., Coulibaly, P. (2006). "Application of support vector machine in Lake water level prediction.” Journal of Hydrological Engineering 11 (3), 199-205.http://dx.doi.org/10.1061/(ASCE)1084-0699(2006)11:3(199).

[7] Lertpalangsunti, N., Chan, C., Mason, R., Tontiwachwuthikul, P. (1999). "A tool set for construction of hybrid intelligent forecasting systems: application for water demand prediction.” Artificial Intelligence in Engineering 13, 21-42.http://dx.doi.org/10.1016/S0954-1810(98)00008-9.

[8] Maidment, D.R., Miaou, S.P. Crawford (1986). "Daily water use in nine cities." Water Resources Research 22 (6), 845851.http://dx.doi.org/10.1029/WR022i006p00845.

[9] Maidment, D.R., Miaou, S.P., Crawford, M.M. (1985). "Transfer function models of daily urban water use." Water Resources Research 21 (4), 425-432.http://dx.doi.org/10.1029/WR021i004p00425.

[10] Salas-LaCruz, J. D. and Yevjevich, V. (1972). Stochastic Structure of Water Use Time Series. Hydrology Paper 52. Colorado State University, Fort Collins, Colorado. 71p.

[11] World Health Organisation [WHO] (1997). Guidelines for drinking-water quality: Surveillance and control of community supplies. Geneva: WHO.

[12] Zhou, S.L., McMahon, T.A., Walton, A., Lewis, J. (2002). "Forecasting operational demand for an urban water supply zone." Journal of Hydrology 259, 189-202.http://dx.doi.org/10.1016/S0022-1694(01)00582-0. 